\title{
Bufadienolides Overcome TRAIL Resistance in Breast Cancer Cells via JAK-STAT Pathway
}

Yokoyama, Sherif Abdelhamed, Yoshihiro Hayakawa and Ikuo Saiki*

Division of Pathogenic Biochemistry, Institute of Natural Medicine, University of Toyama, Toyama, Japan

\begin{abstract}
Aim and objective: Although the clinical significance of tumor necrosis factor-related apoptosis-inducing ligand (TRAIL) has been elucidated, primary or acquired resistance to TRAIL limits its efficacy in cancer patients. This study aimed to investigate bufadienolides as promising candidates to combine with TRAIL and to determine the pathway involved in overcoming TRAIL resistance in breast cancer cells.

Methods: The effects of bufadienolides, cinobufagin and cinobufotalin, in combination with TRAIL were examined in TRAIL-sensitive and TRAIL-resistant breast cancer, MDA-MB-231 and MDA-MB-468 cells, respectively. Cell viability was determined using count and viability assays. Apoptotic cell death was detected by annexin-V/7-AAD staining. Silencing of MCL-1 expression was established using MCL-1 siRNA and protein expression was assessed by Western blot analysis. STAT3 localization was determined using immunofluorescence staining.

Results: The combination of bufadienolides with TRAIL significantly reduced cell viability in both TRAIL-sensitive and TRAIL-resistant breast cancer cells in vitro. Bufadienolides overcame TRAIL resistance by downregulating MCL1 , an anti-apoptotic protein, through the JAK-STAT pathway. The combination of TRAIL with knock down of MCL-1 or JAK-STAT inhibitor, JSI-124, could synergistically induce apoptosis similar to bufadienolides.

Conclusion: Bufadienolides enhance TRAIL-induced apoptosis in breast cancer cells through Mcl-1 downregulation via JAK-STAT pathway. Targeting MCL-1 or JAK2 could be one of the strategies to overcome breast cancer cell resistance to TRAIL. Bufadienolides, through JAK2/STAT3/MCL-1 inhibition, could be considered as promising cancer therapy agents in combination with TRAIL.
\end{abstract}

Keywords: Bufadienolides; MCL-1; Breast cancer; JAK-STAT pathway

\section{Introduction}

Breast cancer is the most frequently diagnosed cancer and the leading cause of cancer death in women in both economically developed and developing countries, accounting for $23 \%$ of total new cancer cases and $14 \%$ of total cancer deaths in 2008 [1]. According to the molecular markers to determine prognosis and treatment, breast cancers can be classified into estrogen receptor (ER)-positive tumors, progesterone receptor (PR)-positive tumors, overexpress one of the members of the epidermal-growth-factor receptor family (HER2/Neu)-positive tumors, or none of these; known as triple-negative breast cancer (TNBC) [2]. Due to its lack of three receptors, TNBC therapy is a difficult clinical challenge because of its unresponsiveness to endocrine therapy or other available targeted therapy.

While endocrine therapy cannot help in the management of TNBC, a promising therapy for various types of cancers including TNBC is tumor necrosis factor-related apoptosis-inducing ligand (TRAIL) because of its high selectivity for various carcinomas over normal cells [3]. TRAIL has been shown to induce apoptosis via both extrinsic (non-mitochondrial) and intrinsic (mitochondrial) pathways [4-6]. Even though the clinical significance of TRAIL has been investigated [7], primary or acquired resistance to TRAIL limits its clinical efficacy in cancer patients $[8,9]$. Several molecules are involved in TRAIL resistance, including the involvement of anti-apoptotic mechanisms (BCL-2, MCL-1, BCL-XL, etc), defects in death receptor signaling (death receptor 4 and death receptor 5), and overexpression of Six 1 [8-12]; however, even though the antitumor effect of TRAIL as a single agent is limited, TRAIL exerts marked antitumor activity upon combination with various cytotoxic drugs $[6,10]$.

It has been reported that chemical compounds from natural products could overcome TRAIL resistance, such as chrysin, curcumin, and wogonin [13-18]. Among these natural products, we focused on two bufadienolides, cinobufagin and cinobufotalin, which are known as cardiotonic steroids, because their antitumor activities as single agents in a wide type of tumors have been previously shown [19-21]. Bufadienolides are the major constituents of cinobufacini extracted from the skin and parotid venom glands of the giant toad Bufo bufo gargarizans Cantor, which has been widely used for thousands of years in China as a cardiotonic, antimicrobial, local anesthetic, and antineoplastic agent in clinical practice [21].

In this study, we demonstrate bufadienolides as promising candidates to TRAIL-based combination therapy, and investigate the molecular pathway involved in its effect to overcome TRAIL resistance in MDA-MB-468 breast cancer cells.

\section{Materials and Methods}

\section{Drugs and reagents}

Cinobufagin and cinobufotalin were purchased from Wako Pure

*Corresponding author: Dr. Ikuo Saiki, Division of Pathogenic Biochemistry, Institute of Natural Medicine, University of Toyama, 2630 Sugitani, Toyama 930-0194, Japan, Tel: +81-76-434-7620; Fax: +81-76-434-5058; E-mail: byosei@inm.u-toyama.ac.jp

Received February 04, 2014; Accepted February 28, 2014; Published March 03 2014

Citation: Hafiyani L, Yokoyama S, Abdelhamed S, Hayakawa Y, Saiki I (2014) Bufadienolides Overcome TRAIL Resistance in Breast Cancer Cells via JAK-STAT Pathway. Altern Integ Med 3: 154. doi:10.4172/2327-5162.1000154

Copyright: $\odot 2014$ Hafiyani L, et al. This is an open-access article distributed under the terms of the Creative Commons Attribution License, which permits unrestricted use, distribution, and reproduction in any medium, provided the original author and source are credited. 
Chemical Industries, Ltd. (Osaka, Japan). Recombinant human TRAIL was purchased from PeproTech (PeproTech, London, UK).

\section{Cell culture}

MDA-MB-231 and MDA-MB-468 (ATCC, Rockville, MD, USA) were cultured in Dulbecco's modified eagle's medium (DMEM) supplemented with $10 \%$ heat-inactivated fetal calf serum, $2 \mathrm{mM}$ L-glutamine, $100 \mathrm{U} / \mathrm{ml}$ penicillin, and $10 \mu \mathrm{g} / \mathrm{ml}$ streptomycin. Cells were maintained at $37^{\circ} \mathrm{C}$ in a humidified atmosphere of $5 \% \mathrm{CO}_{2} / 95 \%$ air.

\section{Count and cell viability assay}

Viability of the cells following treatment was determined using the MUSE Count and Viability Kit (Merck KGaA, Darmstadt, Germany) according to the manufacturer's instructions. Briefly, cinobufagin- or cinobufotalin-containing medium was added at a final concentration of 10,25 , and $50 \mu \mathrm{M}$ and, after $30 \mathrm{~min}$, TRAIL was added. After $24 \mathrm{~h}$ further incubation, all cells were collected and diluted with phosphate buffered saline (PBS) to a concentration of $2 \times 10^{5}$ cells $/ \mathrm{ml}$. $50 \mu \mathrm{l}$ of cell suspension was then added into $450 \mu \mathrm{l}$ MUSE Count and Viability reagent (10x dilution), incubated for $5 \mathrm{~min}$ at room temperature, and analyzed using the MUSE Cell Analyzer. Relative cell viability and synergistic effects were determined as previously described [22,23].

\section{Annexin V \& dead cell assay}

Apoptotic cell number was determined using the MUSE Annexin $\mathrm{V}$ \& Dead Cell Kit (Merck KGaA) according to the manufacturer's instructions. Briefly, after cells were incubated for $24 \mathrm{~h}$, cinobufagin- or cinobufotalin-containing medium was added, cells were incubated for $30 \mathrm{~min}$, and then stimulated with TRAIL. After $12 \mathrm{~h}$ further incubation, all cells were collected and diluted with PBS containing $1 \%$ bovine serum albumin (BSA) as a dilution buffer to a concentration of $5 \times$ $10^{5}$ cells $/ \mathrm{ml} .100 \mu \mathrm{l}$ of cell suspension was then added to $100 \mu \mathrm{l}$ MUSE Annexin V \& dead cell reagent $(2 \times$ dilution), incubated for $20 \mathrm{~min}$ at room temperature, and analyzed using the MUSE Cell Analyzer.

\section{Western blot analysis}

After treatment, whole cell lysates, cytoplasmic extracts, and nuclear extracts were collected as described previously [23]. Equal amounts of protein were resolved by electrophoresis on acrylamide gels. Primary antibodies specific to caspase-3, poly (ADP-ribose) polymerase (PARP), XIAP, MCL-1, BCL-XL, BCL-2, BAX, FLIP, TRAF2, TRAF5, STAT3 and the phosphorylated form of STAT3 (Tyr705 and Ser727), AKT (Ser473), ERK1/2 (Thr202/Tyr204), p65 NF- $\mathrm{B}$ (Ser536) were purchased from Cell Signaling Technology (MA, USA). Primary antibodies specific to $\beta$-actin, AKT, ERK1/2, and p65 NF- $\kappa B$ were purchased from Santa Cruz Biotechnology (Santa Cruz,
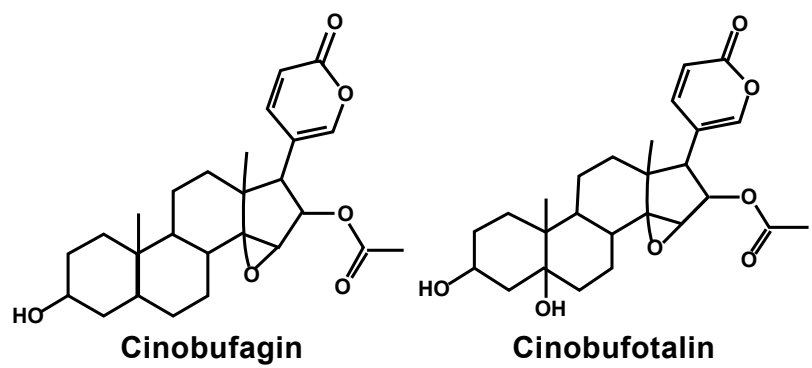

Figure 1a: Chemical structure of cinobufagin and cinobufotalin. Bufadienolides synergistically induce apoptosis with TRAIL in human TNBC cells.

\section{CA, USA).}

\section{Transfection of small interfering RNAs}

Silencing of MCL-1 expression in MDA-MB-468 cells was performed as described previously [13]. Human MCL-1 Stealth RNAi siRNA (HSS181042) was purchased from Invitrogen, (Carlsbad, CA, USA). Firefly luciferase siRNA was obtained from Hokkaido System Science Co. Ltd. (Sapporo, Japan) and used as control siRNA. MDAMB-468 cells were transfected with each siRNA at a final concentration of $20 \mathrm{nM}$, using Lipofectamine RNAiMax (Invitrogen, Carlsbad, CA, USA).

\section{Immunofluorescence staining}

After $12 \mathrm{~h}$ bufadienolide treatment, cells were washed with warm PBS, fixed with $4 \%$ paraformaldehyde for $10 \mathrm{~min}$ at room temperature, permeabilized with $0.1 \%$ Triton-X/PBS for $10 \mathrm{~min}$ at RT and blocked with $1 \%$ BSA $/ 0.1 \%$ Triton-X solution for $1 \mathrm{hr}$ at RT. For the detection of STAT3, cells were incubated with the primary antibody $(\mathrm{x} 100)$ for $12 \mathrm{~h}$ at $4^{\circ} \mathrm{C}$. After washing, cells were treated with secondary antibody $(\mathrm{x} 30)$ using Rhodamine-conjugated swine anti-rabbit IgG (DakoCytomation, Glostrup, Denmark) for $1 \mathrm{~h}$ at RT. Finally, cells were mounted using VECTASHIELD mounting medium containing 4,6-diamidino-2phenylindole (DAPI) (Vector Laboratories, Burlingame, CA). Confocal fluorescence images were observed by LSM700 microscopy and ZEN software (Carl Zeiss, Oberkochen, Germany).

\section{Statistical analysis}

The results are expressed as the mean \pm standard deviation. Statistical significance $(\mathrm{p}<0.05)$ was evaluated by either Student's twotailed t-test or one-way ANOVA followed by the Bonferroni post hoc test, comparing the results to the control.

\section{Results}

\section{Combination with bufadienolides enhances TRAIL-induced} apoptosis in triple-negative breast cancer cells

To evaluate the cytotoxicity of bufadienolides, cinobufagin and cinobufotalin (Figure 1a), and their combination with TRAIL to TNBC cells, we chose TRAIL-sensitive or -resistant TNBC cells, MDA-MB-231 or MDA-MB-468, respectively [22]. Even though bufadienolides have been shown to be anti-tumor agents [19-21], these compounds showed limited cytotoxicity in both TNBC cell lines (Figure 1b). Interestingly, both bufadienolides could significantly increase TRAIL-induced cytotoxicity in TNBC cells, even in TRAIL-resistant cells, MDA-MB-468 cells, compared to single therapy with TRAIL or bufadienolides alone.

We next examined whether bufadienolides overcome TRAIL resistance in TRAIL-resistant cells through apoptosis, because only the combination of bufadienolides with TRAIL could show cytotoxicity even in MDA-MB- 468 cells, without any cytotoxicity by either bufadienolides or TRAIL alone. Annexin-V-positive cells were increased in TRAIL/ bufadienolide-treated cells compared with non-treated, TRAIL-treated, or bufadienolide-treated cells (Figure 1c). In addition, the cleavage of pro-caspase-3, and poly (ADP-ribose) polymerase (PARP) protein were detected as hallmarks of apoptosis only in TRAIL/bufadienolidetreated cells (Figure 1d). These data suggest that bufadienolides could overcome TRAIL resistance in TRAIL-resistant TNBC cells.

\section{Bufadienolides suppress MCL-1 expression}

To identify the mechanisms by which bufadienolides overcome TRAIL resistance, we further examined several proteins related to 

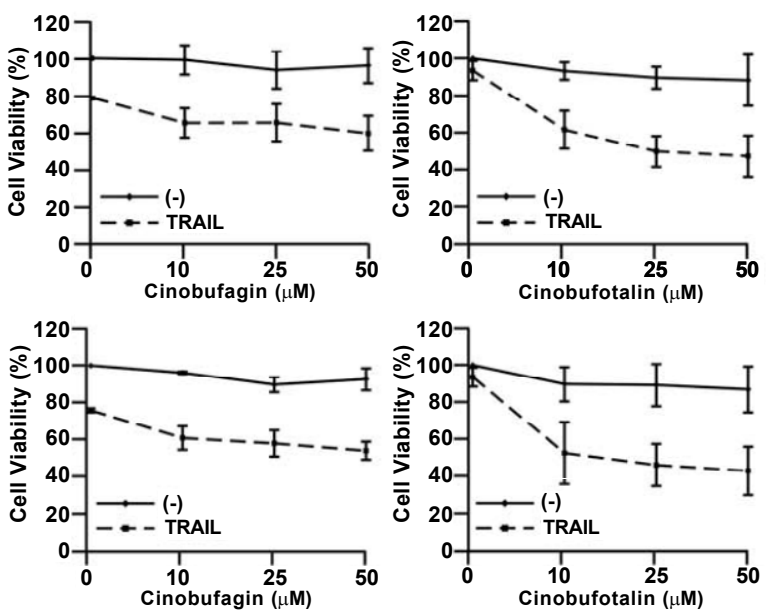

Figure 1b: MDA-MB-231 and MDA-MB-468 cells were pretreated with cinobufagin or cinobufotalin at various concentrations $(10 \mu \mathrm{M}, 25 \mu \mathrm{M}$, and $50 \mu \mathrm{M})$ for $30 \mathrm{~min}$, followed with or without TRAIL $(50 \mathrm{ng} / \mathrm{mL})$ for 24 h. Cell viability was determined by count and cell viability assays.

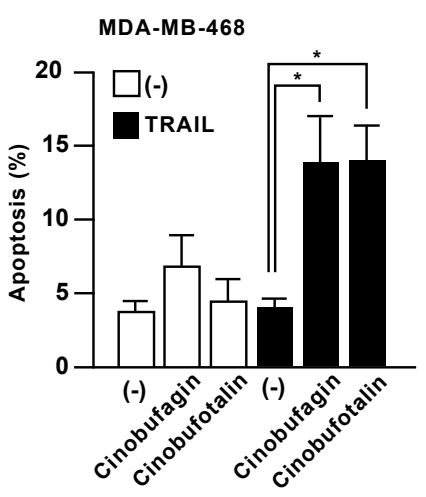

Figure 1c: MDA-MB-468 cells were pretreated with $25 \mu \mathrm{M}$ cinobufagin or cinobufotalin for $30 \mathrm{~min}$, followed with or without TRAIL $(50 \mathrm{ng} / \mathrm{mL})$ for $12 \mathrm{~h}$. Total apoptotic cells were determined by Annexin $\mathrm{V}$ and dead cell assays. ${ }^{*} p<0.01$ vs. non-treated cells by one-way ANOVA followed by the Bonferroni test, $\mathrm{n}=3$

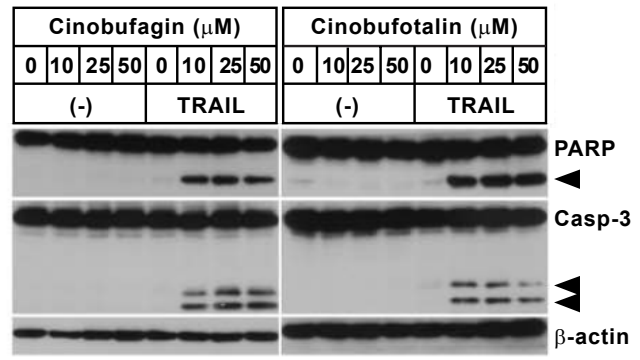

Figure 1d: MDA-MB-468 cells were pretreated with cinobufagin or cinobufotalin at various concentrations $(10 \mu \mathrm{M}, 25 \mu \mathrm{M}$, and $50 \mu \mathrm{M})$ for $30 \mathrm{~min}$, followed with or without TRAIL $(50 \mathrm{ng} / \mathrm{mL})$ for $12 \mathrm{~h}$. Whole cell extract was subjected to Western blot analysis using antibodies against the indicated proteins. Arrows indicate cleaved forms of caspase- 3 and PARP.

either intrinsic (BCL-2, BCL-XL, MCL-1, BAX) or extrinsic (TRAF2, TRAF5, XIAP, FLIP) pathways of TRAIL in MDA-MB-468 cells [4-6]. Both cinobufagin and cinobufotalin could selectively suppress MCL-
1 expression with either bufadienolide alone or in combination with TRAIL (Figure 2a). We also confirmed the time- and dose-dependent MCL-1 suppression in concert with the induction of apoptotic markers (Figure 2b), suggesting that MCL-1 could be involved in overcoming TRAIL resistance.

\section{Silencing MCL-1 expression is sufficient to overcome TRAIL resistance in MDA-MB-468 cells}

To investigate its role in overcoming TRAIL resistance, MCL-1 was knocked down in MDA-MB-468 cells using siRNA against MCL-1 (siMCL-1). The cleavage of caspase- 3 and PARP could be detected only in siMCL-1-transfected cells with TRAIL (Figure 3a). Consistently, we could also detect apoptosis by using annexin V staining in siMCL-1transfected cells treated with TRAIL (Figure 3b). Taken together, MCL1 downregulation is sufficient to overcome TRAIL resistance in MDAMB-468, and to induce apoptosis with TRAIL.

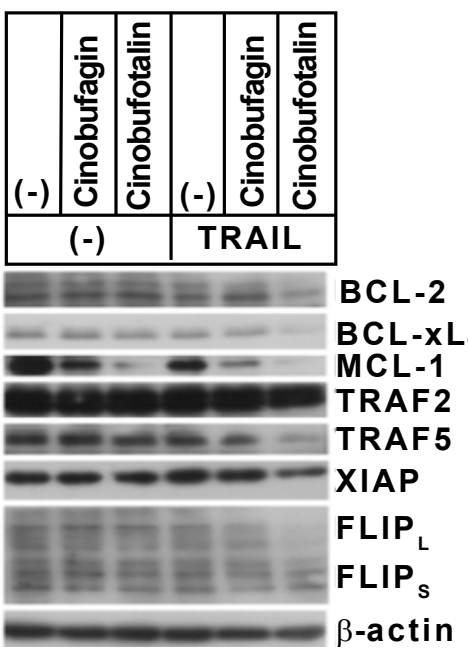

Figure 2a: Bufadienolides suppress MCL-1 expression. Whole cell extract was subjected to Western blot analysis against the indicated proteins related with the intrinsic and extrinsic death pathways of TRAIL. Arrows indicate two forms of FLIP. Other conditions were similar to figure $1 \mathrm{c}$.

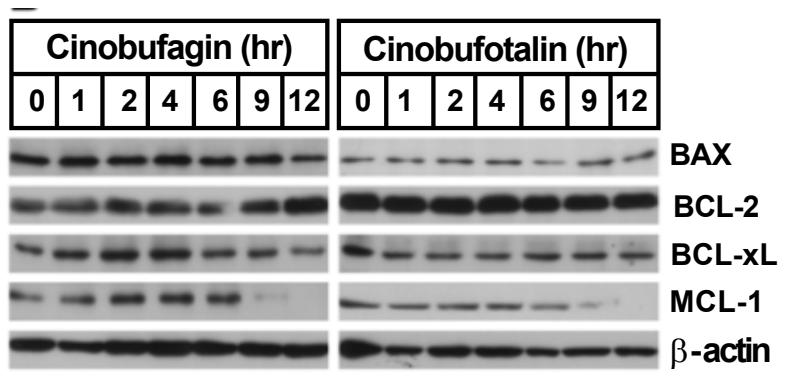

Figure 2b: MDA-MB-468 cells were treated with $25 \mu \mathrm{M}$ cinobufagin or cinobufotalin for the indicated time. Whole cell extract was subjected to Western blot analysis. 
Citation: Hafiyani L, Yokoyama S, Abdelhamed S, Hayakawa Y, Saiki I (2014) Bufadienolides Overcome TRAIL Resistance in Breast Cancer Cells via JAK-STAT Pathway. Altern Integ Med 3: 154. doi:10.4172/2327-5162.1000154

Page 4 of 7

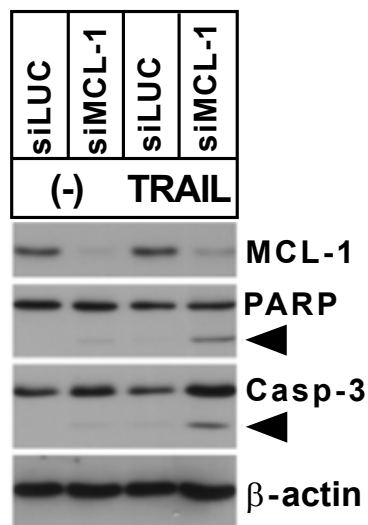

Figure 3a: Silencing MCL-1 expression is sufficient to overcome TRAIL resistance in MDA-MB-468 cells. MDA-MB-468 cells were transfected with siRNA against luciferase and MCL-1 for $24 \mathrm{~h}$, followed with or without TRAIL ( $50 \mathrm{ng} / \mathrm{mL}$ ) for $12 \mathrm{~h}$. Whole cell extract was subjected to Western blot analysis using antibodies against the indicated proteins.

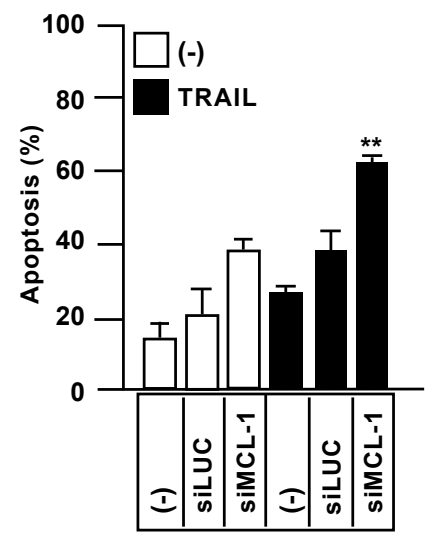

Figure 3b: The cells were subjected to Annexin $V$ and dead cell assays. Other conditions were similar to figure $3 a$.

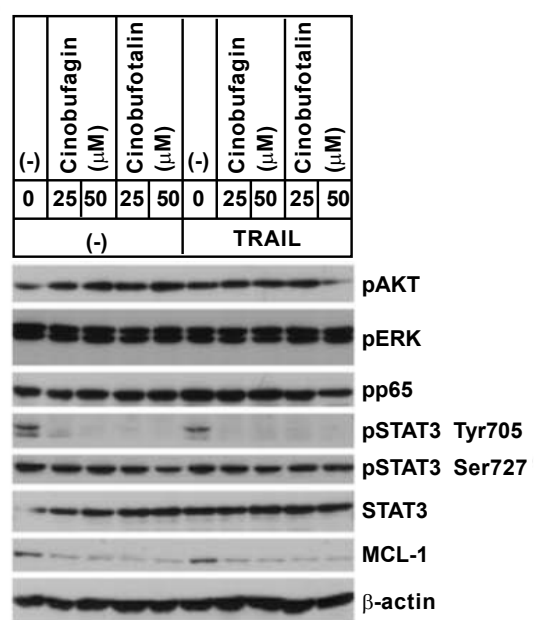

Figure 4a: Inhibition of STAT3 Tyr705 phosphorylation and nuclear translocation mediates MCL-1 downregulation by bufadienolides in MDAMB-468 cells. MDA-MB-468 cells were pretreated with cinobufagin or cinobufotalin at $25 \mu \mathrm{M}$ and $50 \mu \mathrm{M}$ for $30 \mathrm{~min}$, followed with or without TRAIL $(50 \mathrm{ng} / \mathrm{mL})$ for $12 \mathrm{~h}$. Whole cell extract was subjected to Western blot analysis using antibodies against the indicated proteins.
Inhibition of STAT3 phosphorylation and nuclear translocation mediate MCL-1 downregulation by bufadienolides in MDA-MB-468 cells

We further examined the effects of bufadienolides on several MCL-1 upstream proteins related to AKT, ERK, NF- $\mathrm{KB}$, and STAT pathways [24]. Amongst these proteins, bufadienolides markedly suppressed constitutive STAT3 tyrosine phosphorylation (Tyr705), which is necessary for STAT3 translocation to the nucleus and its transcriptional activity in the targeted genes, including MCL-1 $[25,26]$. The downregulation of pSTAT3 Tyr705 by bufadienolides was highly correlated to the decrease of MCL-1 protein in a dose- and time-dependent manner (Figures $4 \mathrm{a}$ and $4 \mathrm{~b}$ ). The phosphorylation at Ser727 of STAT3 could not be inhibited by bufadienolides, indicating that its inhibitory activity is specific to tyrosine kinases but not to serine/threonine kinases. To check the STAT3 nuclear localization, we performed immunofluorescence staining and Western blot analysis (Figures $4 \mathrm{c}$ and $4 \mathrm{~d}$ ). After bufadienolide treatments, STAT3 showed a ring-like appearance, indicating its localization in cytoplasm, while it was distributed evenly and diffusively both in the nucleus and cytoplasm of non-treated cells (Figure 4c). Similar to immunofluorescent staining, we could detect the suppression of nuclear STAT3 by Western blot

\begin{tabular}{|l|l|l|l|l|l|l|l|l|l|l|l|l|l|}
\hline \multicolumn{7}{|c|}{ Cinobufagin (hr) } & \multicolumn{7}{|c|}{ Cinobufotalin (hr) } \\
\hline 0 & 1 & 2 & 4 & 6 & 9 & 12 & 0 & 1 & 2 & 4 & 6 & 9 & 12 \\
\hline \\
\hline-0
\end{tabular}

Figure 4b: Whole cell extract was subjected to Western blot analysis Other conditions were similar to figure $2 \mathrm{~b}$.

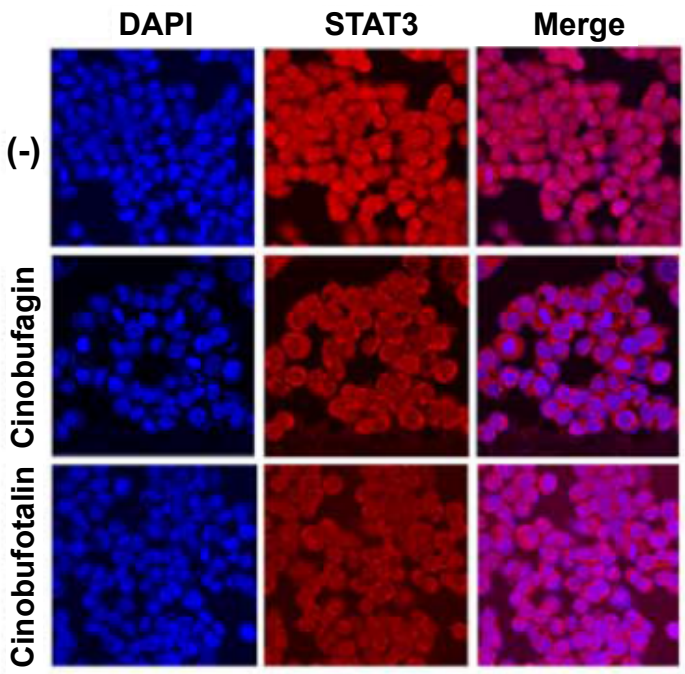

Figure 4c: MDA-MB-468 cells were treated with $25 \mu \mathrm{M}$ cinobufagin or cinobufotalin for $12 \mathrm{~h}$ and subjected to immunofluorescence staining using STAT3 antibody and Rhodamine-conjugated swine anti-rabbit IgG. 


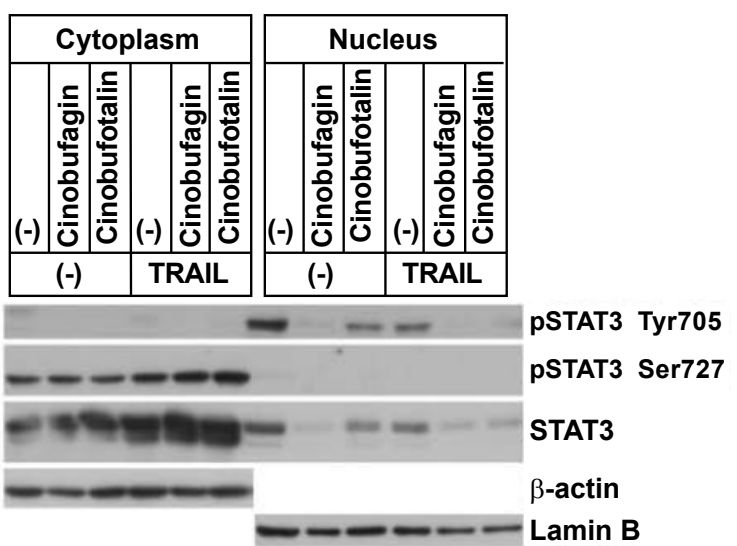

Figure 4d: Cytoplasmic fraction and nuclear fraction were prepared and subjected to Western blot analysis. Other conditions were similar to figure 2a.

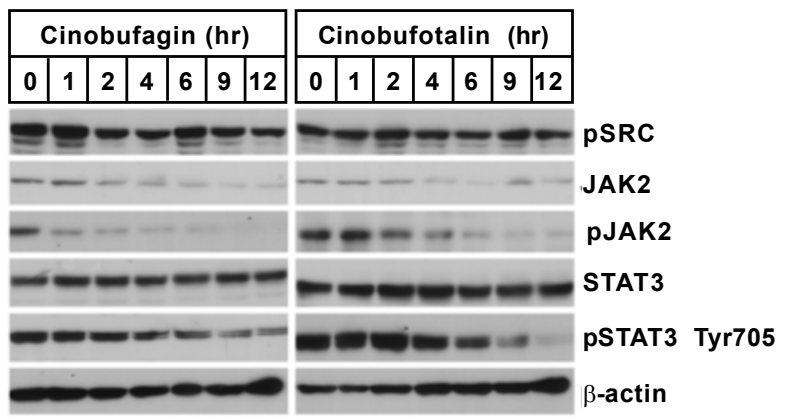

Figure 5a: JAK2 inhibition is sufficient for synergistic effects of bufadienolides with TRAIL in MDA-MB-468 cells. MDA-MB-468 cells were treated with $25 \mathrm{mM}$ cinobufagin or cinobufotalin for the indicated time. Whole cell extract was subjected to Western blot analysis using antibodies against the indicated proteins

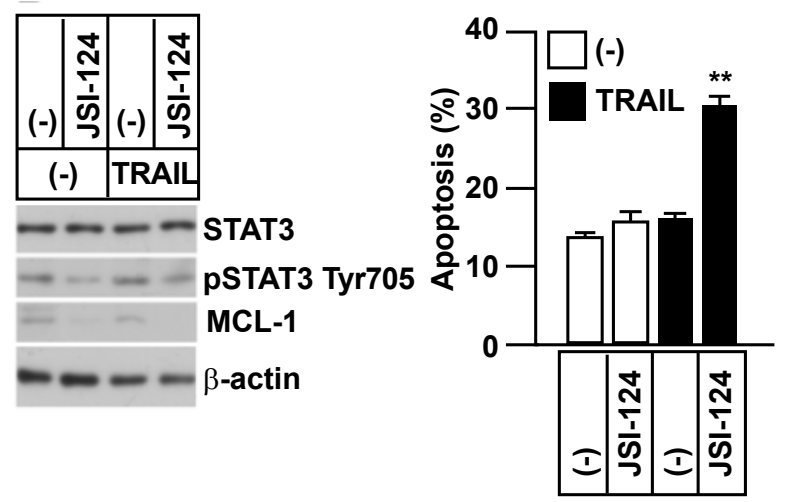

Figure 5b: MDA-MB-468 cells were treated with $1 \mu \mathrm{M}$ JAK-STAT inhibitor, JSI-124, and TRAIL $(50 \mathrm{ng} / \mathrm{ml})$ for $12 \mathrm{~h}$ and subjected to Western blot analysis (left) and annexin $\mathrm{V}$ and dead cell assays (right).

analysis without any change of phosphorylated STAT3 at Ser727 (Figure $4 \mathrm{~d}$ ). Collectively, these data suggested that the phosphorylation at Tyr705 of STAT3 was the target of bufadienolides, leading to the inhibition of the nuclear translocation and transcriptional activity of STAT3 in MDA-MB-468 cells.

\section{JAK2 inhibition is sufficient to show synergistic effects of bufadienolides with TRAIL in MDA-MB-468 cells}

To identify the upstream target of bufadienolides, we focused on the two major tyrosine kinases involved in STAT3 phosphorylation in breast cancer cells: JAK2 and Src [25-29]. Both the protein expression and phosphorylation of JAK2 were decreased by bufodienolides, while phosphorylation of Src remained unaffected (Figure 5a), suggesting that the downregulation of STAT3 phosphorylation by bufadienolides might be caused by suppression of JAK2 protein expression in MDA-MB-468 cells. Finally, to confirm the significance of the JAK-STAT pathway in overcoming TRAIL resistance, we inhibited the JAK-STAT pathway by using $1 \mu \mathrm{M}$ JSI-124 (Cucurbitacin I) [30]. Strikingly, the combination of JSI-124 and TRAIL was sufficient to sensitize cancer cells to TRAIL, even though either JSI-124 or TRAIL alone could not induce apoptosis (Figure 5b). These results suggest that overcoming TRAIL resistance by bufadienolides could be mediated through inhibition of the JAK2STAT3 pathway.

\section{Discussion}

Our study showed that the combination of TRAIL and bufadienolides synergistically induced apoptosis in TRAIL-sensitive and even in TRAIL-resistant TNBC cells in vitro. Furthermore, bufadienolides enhanced apoptosis by decreasing MCL-1 expression, which is mediated through JAK2/STAT3 Tyr705 phosphorylation pathways.

Although TRAIL-based therapies, including anti-death receptor 5 agonistic antibody, have provided a significant clinical benefit in some cancer patients in clinical trials [7], the acquisition of drug resistance is known to limit the efficacy of TRAIL-based therapy [8,9]. Moreover, there are some inherently TRAIL-resistant breast cancers, and TRAIL resistance can also be acquired by cells that were originally TRAIL sensitive [10]. There is some evidence that BCL-2 family members containing MCL-1 are involved in TRAIL-resistance in cancer cells by enhancing the intrinsic pathways of TRAIL [31-35]. Consistently, we showed that knocking down MCL-1 is sufficient to overcome TRAIL resistance in MDA-MB-468 cells (Figure 3), regardless a lack of change in the caspase- 8 or other extrinsic and intrinsic pathwayrelated proteins (Figure 2). Similar to MDA-MB-468 cells, MCL-1 downregulation is sufficient to overcome TRAIL resistance in A549 human lung adenocarcinoma cells [13]. Further investigation is still needed to confirm the significance of MCL-1 in other types of TRAILresistant cancers and its role in determining TRAIL-resistant cell lines compared to TRAIL-sensitive cells. However, our results and those reported previously suggest that MCL-1 is one of the most important molecules for TRAIL-based therapy and could be a good therapeutic target to overcome TRAIL resistance.

Although an MCL-1 inhibitor is a good candidate for combination therapy with TRAIL, it has been difficult to target only MCL-1 itself by BCL- 2 family inhibitors. In addition to MCL-1, we identified the significance of the JAK2-STAT3 pathway in overcoming TRAIL resistance by bufadienolides (Figure 4 and 5). Clinically, persistent activation of STAT3 has been shown in a variety of human cancers, including pancreatic, prostate, ovarian, hepatic, and breast carcinomas, as well as in hematopoietic tumors, including lymphomas and leukemia [36-42], and also has been correlated with a poor prognosis $[36,43]$. In addition to constitutive active STAT3, IL-6 production in primary breast cancers plays a critical role in activating the JAK-STAT pathway and is widely known to be highly correlated with tumor cell proliferation, advanced stage breast cancers, and poor prognosis [44] 
Citation: Hafiyani L, Yokoyama S, Abdelhamed S, Hayakawa Y, Saiki I (2014) Bufadienolides Overcome TRAIL Resistance in Breast Cancer Cells via JAK-STAT Pathway. Altern Integ Med 3: 154. doi:10.4172/2327-5162.1000154

Given that human breast cancers produce more IL-6, which activates the JAK/STAT pathway, than matched healthy breast tissue, inhibition of the JAK-STAT pathway could be a promising target for breast cancer therapy.

We determined that bufadienolides suppressed MCL-1 expression via the JAK-STAT pathway; however our study could not exclude the possibility that other pathways were also involved in its effect on TRAIL sensitization. Previously, Bufadienolides have been shown to be cardiac glycosides, potent $\mathrm{Na}^{+} \mathrm{K}^{+}$-ATPase inhibitors. Ouabain, also a cardiac glycoside, could suppress MCL-1 through ROS-mediated proteasomal degradation [45]. Another cardiac glycoside, thevefolin, overcomes TRAIL-resistance through enhancing the expression of TRAIL receptors in gastric cancer [46]. In addition to their role in TRAILinduced apoptosis, inhibition of $\mathrm{Na}^{+} \mathrm{K}^{+}$-ATPase by cardiac glycosides is important for overcoming multi-drug resistance and promoting anoikis [47,48], suggesting another possible role for cardiac glycosides in cancer therapy.

Taken together, pending further in vivo and clinical experiments to determine safe and optimal doses, bufadienolides or JAK inhibitors can be considered not only as adjuvants with TRAIL but also as single agents for triple-negative breast cancer therapy.

\section{Acknowledgement}

We thank all members of the Saiki laboratory for discussions and suggestions. This study was supported in part by a Grant-in-Aid for Young Scientists (B) (No.24700971) (S.Y.), by Grant-in-aid for Challenging Exploratory Research 24659348 (I.S.) from the Ministry of Education, Culture, Sports, Science, and Technology (Japan), by The YASUDA Medical Foundation (S.Y.), by a Grant-inAid for the Cooperative Research Project (I.S.) from Joint Usage/Research Center (Joint Usage/Research Center for Science-Based Natural Medicine), Institute of Natural Medicine, University of Toyama in 2013.

\section{References}

1. Jemal A, Bray F, Center MM, Ferlay J, Ward E, et al. (2011) Global cancer statistics. CA Cancer J Clin 61: 69-90.

2. Perou CM (2010) Molecular stratification of triple-negative breast cancers Oncologist 15 Suppl 5: 39-48.

3. Keane MM, Ettenberg SA, Nau MM, Russell EK, Lipkowitz S (1999) Chemotherapy augments TRAIL-induced apoptosis in breast cell lines. Cancer Res 59: 734-741.

4. Ashkenazi A, Pai RC, Fong S, Leung S, Lawrence DA, et al. (1999) Safety and antitumor activity of recombinant soluble Apo2 ligand. J Clin Invest 104: 155-162.

5. Johnstone RW, Frew AJ, Smyth MJ (2008) The TRAIL apoptotic pathway in cancer onset, progression and therapy. Nat Rev Cancer 8: 782-798.

6. Walczak H, Miller RE, Ariail K, Gliniak B, Griffith TS, et al. (1999) Tumoricida activity of tumor necrosis factor-related apoptosis-inducing ligand in vivo. Nat Med 5: 157-163.

7. Bellail AC, Qi L, Mulligan P, Chhabra V, Hao C (2009) TRAIL agonists on clinical trials for cancer therapy: the promises and the challenges. Rev Recent Clin Trials 4: 34-41.

8. Dyer MJ, MacFarlane M, Cohen GM (2007) Barriers to effective TRAIL-targeted therapy of malignancy. J Clin Oncol 25: 4505-4506.

9. Tolcher AW, Mita M, Meropol NJ, von Mehren M, Patnaik A, et al. (2007) Phase I pharmacokinetic and biologic correlative study of mapatumumab, a fully human monoclonal antibody with agonist activity to tumor necrosis factorrelated apoptosis-inducing ligand receptor-1. J Clin Oncol 25: 1390-1395.

10. Thorburn A, Behbakht K, Ford H (2008) TRAIL receptor-targeted therapeutics: resistance mechanisms and strategies to avoid them. Drug Resist Updat 11: $17-24$

11. Behbakht K, Qamar L, Aldridge CS, Coletta RD, Davidson SA, et al. (2007) Six1 overexpression in ovarian carcinoma causes resistance to TRAIL-mediated apoptosis and is associated with poor survival. Cancer Res 67: 3036-3042.
12. Wagner KW, Punnoose EA, Januario T, Lawrence DA, Pitti RM, et al. (2007) Death-receptor O-glycosylation controls tumor-cell sensitivity to the proapoptotic ligand Apo2L/TRAIL. Nat Med 13: 1070-1077.

13. Lirdprapamongkol K, Sakurai H, Abdelhamed S, Yokoyama S, Athikomkulchai S, et al. (2013) Chrysin overcomes TRAIL resistance of cancer cells through Mcl-1 downregulation by inhibiting STAT3 phosphorylation. Int J Oncol 43: 329 337.

14. Deeb D, Jiang H, Gao X, Hafner MS, Wong H, et al. (2004) Curcumin sensitizes prostate cancer cells to tumor necrosis factor-related apoptosis-inducing ligand/Apo2L by inhibiting nuclear factor-kappaB through suppression of IkappaBalpha phosphorylation. Mol Cancer Ther 3: 803-812.

15. Ding J, Polier G, Kohler R, Giaisi M, Krammer PH, et al. (2012) Wogonin and related natural flavones overcome tumor necrosis factor-related apoptosisinducing ligand (TRAIL) protein resistance of tumors by down-regulation of c-FLIP protein and up-regulation of TRAIL receptor 2 expression. J Biol Chem 287: 641-649.

16. Hasegawa H, Yamada Y, Komiyama K, Hayashi M, Ishibashi M, et al. (2006) Dihydroflavonol BB-1, an extract of natural plant Blumea balsamifera, abrogates TRAIL resistance in leukemia cells. Blood 107: 679-688.

17. Jeon KI, Rih JK, Kim HJ, Lee YJ, Cho CH, et al. (2003) Pretreatment of indole3-carbinol augments TRAIL-induced apoptosis in a prostate cancer cell line LNCaP. FEBS Lett 544: 246-251.

18. Szliszka E, Sokol-Letowska A, Kucharska AZ, Jaworska D, Czuba ZP, et al. (2013) Ethanolic Extract of Polish Propolis: Chemical Composition and TRAIL-R2 Death Receptor Targeting Apoptotic Activity against Prostate Cancer Cells. Evid Based Complement Alternat Med 2013: 757628

19. Emam H, Zhao QL, Furusawa Y, Refaat A, Ahmed K, et al. (2012) Apoptotic cell death by the novel natural compound, cinobufotalin. Chem Biol Interact 199: 154-160.

20. Ma L, Song B, Jin H, Pi J, Liu L, et al. (2012) Cinobufacini induced MDA MB-231 cell apoptosis-associated cell cycle arrest and cytoskeleton function Bioorg Med Chem Lett 22: 1459-1463.

21. Qi F, Li A, Inagaki Y, Kokudo N, Tamura S, et al. (2011) Antitumor activity of extracts and compounds from the skin of the toad Bufo bufo gargarizans Cantor. Int Immunopharmacol 11: 342-349.

22. Abdelhamed S, Yokoyama S, Hafiyani L, Kalauni SK, Hayakawa Y, et al. (2013) Identification of plant extracts sensitizing breast cancer cells to TRAIL. Oncol Rep 29: 1991-1998.

23. Sakurai H, Suzuki S, Kawasaki N, Nakano H, Okazaki T, et al. (2003) Tumor necrosis factor-alpha-induced IKK phosphorylation of NF-kappaB p65 on serine 536 is mediated through the TRAF2, TRAF5, and TAK1 signaling pathway. J Biol Chem 278: 36916-36923

24. Akgul C (2009) Mcl-1 is a potential therapeutic target in multiple types of cancer. Cell Mol Life Sci 66: 1326-1336.

25. Berclaz G, Altermatt HJ, Rohrbach V, Siragusa A, Dreher E, et al. (2001) EGFR dependent expression of STAT3 (but not STAT1) in breast cancer. Int J Oncol 19: $1155-1160$.

26. Berishaj M, Gao SP, Ahmed S, Leslie K, Al-Ahmadie H, et al. (2007) Stat3 is tyrosine-phosphorylated through the interleukin-6/glycoprotein 130/Janus kinase pathway in breast cancer. Breast Cancer Res 9: R32.

27. Garcia R, Bowman TL, Niu G, Yu H, Minton S, et al. (2001) Constitutive activation of Stat3 by the Src and JAK tyrosine kinases participates in growth regulation of human breast carcinoma cells. Oncogene 20: 2499-2513.

28. Rawlings JS, Rosler KM, Harrison DA (2004) The JAK/STAT signaling pathway. J Cell Sci 117: 1281-1283.

29. Seavey MM, Dobrzanski P (2012) The many faces of Janus kinase. Biochem Pharmacol 83: 1136-1145.

30. Blaskovich MA, Sun J, Cantor A, Turkson J, Jove R, et al. (2003) Discovery of JSI-124 (cucurbitacin I), a selective Janus kinase/signal transducer and activator of transcription 3 signaling pathway inhibitor with potent antitumo activity against human and murine cancer cells in mice. Cancer Res 63: 1270 1279

31. Dong Y, Yin S, Li J, Jiang C, Ye M, et al. (2011) Bufadienolide compounds sensitize human breast cancer cells to TRAIL-induced apoptosis via inhibition of STAT3/Mcl-1 pathway. Apoptosis 16: 394-403. 
Citation: Hafiyani L, Yokoyama S, Abdelhamed S, Hayakawa Y, Saiki I (2014) Bufadienolides Overcome TRAIL Resistance in Breast Cancer Cells via JAK-STAT Pathway. Altern Integ Med 3: 154. doi:10.4172/2327-5162.1000154

Page 7 of 7

32. Kim SH, Ricci MS, El-Deiry WS (2008) Mcl-1: a gateway to TRAIL sensitization. Cancer Res 68: 2062-2064.

33. Qi F, Inagaki Y, Gao B, Cui X, Xu H, et al. (2011) Bufalin and cinobufagin induce apoptosis of human hepatocellular carcinoma cells via Fas- and mitochondriamediated pathways. Cancer Sci 102: 951-958.

34. Su CL, Lin TY, Lin CN, Won SJ (2009) Involvement of caspases and apoptosisinducing factor in bufotalin-induced apoptosis of Hep 3B cells. J Agric Food Chem 57: 55-61.

35. Waiwut P, Inujima A, Inoue H, Saiki I, Sakurai H (2012) Bufotalin sensitizes death receptor-induced apoptosis via Bid- and STAT1-dependent pathways. Int J Oncol 40: 203-208.

36. Al Zaid Siddiquee K1, Turkson J (2008) STAT3 as a target for inducing apoptosis in solid and hematological tumors. Cell Res 18: 254-267.

37. Trevino JG, Gray MJ, Nawrocki ST, Summy JM, Lesslie DP, et al. (2006) Src activation of Stat3 is an independent requirement from NF-kappaB activation for constitutive IL-8 expression in human pancreatic adenocarcinoma cells. Angiogenesis 9: 101-110.

38. Abdulghani J, Gu L, Dagvadorj A, Lutz J, Leiby B, et al. (2008) Stat3 promotes metastatic progression of prostate cancer. Am J Pathol 172: 1717-1728.

39. Burke WM, Jin X, Lin HJ, Huang M, Liu R, et al. (2001) Inhibition of constitutively active Stat3 suppresses growth of human ovarian and breast cancer cells. Oncogene 20: 7925-7934.

40. Kortylewski M, Kujawski M, Wang T, Wei S, Zhang S, et al. (2005) Inhibiting Stat3 signaling in the hematopoietic system elicits multicomponent antitumor immunity. Nat Med 11: 1314-1321.
41. Cheng F, Wang HW, Cuenca A, Huang M, Ghansah T, et al. (2003) A critical role for Stat3 signaling in immune tolerance. Immunity 19: 425-436.

42. Li Y, Du H, Qin Y, Roberts J, Cummings OW, et al. (2007) Activation of the signal transducers and activators of the transcription 3 pathway in alveolar epithelial cells induces inflammation and adenocarcinomas in mouse lung. Cancer Res 67: 8494-8503.

43. Yu H, Pardoll D, Jove R (2009) STATs in cancer inflammation and immunity: a leading role for STAT3. Nat Rev Cancer 9: 798-809.

44. Sullivan NJ (2011) Interleukin-6 in the Breast Tumor Microenvironment: Breast Cancer - Focusing Tumor Microenvironment, Stem cells and Metastasis. InTech, Rijeka, Croatia.

45. Chanvorachote P, Pongrakhananon V (2013) Ouabain downregulates Mcl-1 and sensitizes lung cancer cells to TRAIL-induced apoptosis. Am J Physiol Cell Physiol 304: C263-272.

46. Miyagawa T, Ohtsuki T, Koyano T, Kowithayakorn T, Ishibashi M (2009) Cardenolide glycosides of Thevetia peruviana and triterpenoid saponins of Sapindus emarginatus as TRAIL resistance-overcoming compounds. J Nat Prod 72: 1507-1511.

47. Mijatovic T, Jungwirth U, Heffeter P, Hoda MA, Dornetshuber R, et al. (2009) The $\mathrm{Na}+/ \mathrm{K}+-\mathrm{ATP}$ ase is the Achilles heel of multi-drug-resistant cancer cells. Cancer Lett 282: 30-34.

48. Simpson CD, Mawji IA, Anyiwe K, Williams MA, Wang X, et al. (2009) Inhibition of the sodium potassium adenosine triphosphatase pump sensitizes cancer cells to anoikis and prevents distant tumor formation. Cancer Res 69: 27392747. 